\title{
FACTORES CULTURALES EN LA FORMACIÓN Y CAPACITACIÓN PROFESIONAL
}

\author{
Denis BurnetT
}

\section{PRESENTACIÓN}

El enfoque que se desarrolla en este documento intenta una sistematización de aquellos factores que se encuentran interrelacionados desde un punto de vista cultural y que es necesario tomar en cuenta para la formulación exitosa de políticas de capacitación y formación profesional. También se recomienda la consideración de estos factores en cualquier programa concreto de capacitación en y fuera de las empresas.

El presente artículo se inicia con la exposición del marco teórico. A partir de éste y sobre la base de antecedentes disponibles (y que son el resultado de investigaciones realizadas), se define un conjunto de características relativas a los éthos laboral y empresarial en Chile. Finalmente, se plantean algunas recomendaciones para ser incorporadas en las políticas y programas de formación y capacitación laboral.

El estudio tiene un carácter exploratorio y sus conclusiones no pueden generalizarse para ningún universo. Sin embargo la diversidad de las fuentes secundarias consideradas y el propio estudio realizado por el autor dan sustentabilidad a las hipótesis del documento. La investigación se basa en antecedentes disponibles sobre relaciones laborales en Chile, aunque se estima que algunas de las conclusiones pueden extrapolarse en su carácter de hipótesis de trabajo a otros países de América Latina. Con respecto a las recomendaciones (punto seis) éstas tienen una validez -aunque variando según las condiciones en cada país y empresa- que excede la del análisis del caso chileno.

No obstante las limitaciones de este estudio, donde fue posible se consideraron antecedentes relativos a otros países de América Latina, estableciendo, aunque insuficientemente, una base de comparación e inferencia.

Este estudio fue realizado para el Proyecto Conjunto CEPAL/GTZ Políticas para mejorar la Calidad, Eficiencia y la Relevancia del Entrenamiento Profesional en América Latina y el Caribe'. No obstante se advierte que las opiniones expresadas en este artículo son de exclusiva responsabilidad del autor. 


\section{MARCO TEÓRICO Y METODOLÓGICO}

\section{I. El concepto de profesión}

En 'La ética protestante y el espíritu del Capitalismo' Max Weber estableció el origen ideológico del capitalismo en el 'obrar bien' calvinista como profesión.' De hecho, la investigación del espíritu del capitalismo se centra en el moderno concepto de profesión. 'beruf', como sistema de actividades prescritas que exigen su realización disciplinada para garantizar el 'obrar bien en el Mundo'.

En su análisis del tex to 'Christian Directory' de Baxter, Weber establece la correspondencia entre el lucro obtenido en el desempeño de una profesión y la manifestación de la gracia divina en la Ética Calvinista. La gracia divina se vincularía estrechamente con el premio que la sociedad entrega al trabajo bien realizado y de utilidad pública (la ganancia sería una manifestación de la complacencia divina frente al bien obrar). Como se rechaza el consumo suntuario y se fomenta la frugalidad el resuitado es la acumulación. Con el Calvinismo el enriquecerse se libera de todas las trabas morales y se transforma en el motor del desarrollo capitalista.

Del análisis de Weber sobresale esta elevación del lucro en el desempeño de la profesión en la génesis de las relaciones capitalistas. Frente a la pobreza como ideal católico, el lucro, como manifestación de la gracia divina, sin duda tiene un carácter subversivo, lo que lo hace tanto más 'llamativo'. Pero lo esencial del análisis de Weber no es el establecimiento del carácter de 'bien ético' de la ganancia (aunque éste sea un estímulo fundamental al desarrollo del capitalismo), sino el del concepto calvinista del obrar bien que requiere el arreglo sistemático de actividades normadas, en la moderna forma de profesión. Es el ejercicio de la profesión el que asegura a la persona que está obrando bien. En este contexto la ganancia no es más que una de las manifestaciones, aunque no la única, de la gracia divina (el lucro confirma, en forma material, la presencia de voluntad divina).

De allí que necesaria al espíritu del capitalismo es la existencia de una clase trabajadora disciplinada y frugal. Este profesionalismo de las clases trabajadoras es destacado por Weber al analizar su desempeño, que ya no depende de una orientación 'tradicional' a la satisfacción de necesidades, sino que al obrar bien en el trabajo. En esta lectura, para la naciente clase obrera calvinista no era el lucro su motor para la disciplina en el trabajo sino que el ejercicio de la profesión. ${ }^{2}$

\section{2. La profesionalización de la sociedad no es un fenómeno originado exclusivamente a nivel económico}

De acuerdo a Weber es sólo con la generalización (automatismo) de relaciones de mercado capitalistas que se establece la hegemonía sin contrapeso del lucro como motor de la acumulación (el lucro como manifestación del éxito personal, como medio para la adquisición de bienes materiales, etc.), estando su génesis en el moderno concepto de profesión establecido por el espíritu capitalista original. Sin embargo en Weber el origen del concepto moderno de profesión queda establecido (se genera) en el plano religioso, es decir en un plano muy distinto al plano de la economía y de la educación. Es este concepto religioso que permea todas las relaciones sociales. Lo central de la ética calvinista -en la lectura que de ella hace Weber- es el concepto de profesión que garantiza bajo la forma de disciplina el obrar bien en el mundo. Es obvio que esta reglamentación y sistematización de

1 M. Weber: "La Ética Protestante y el Espiritu del Capitalismo": Península: 1997

$2 \mathrm{M}$. Weber hace particular hincapié en esto al referirse a las dificulades en elevar la productividad de los trabajadores a partir de incentivos monetarios. 
conocimientos es aplicada como método a todas las actividades sociales (y no sólo a las económicas). La vida en el mundo en todas sus facetas ha de garantizar este buen obrar. De allí que no es sorprendente que las sociedades sujetas a la revolución calvinista tengan una fuerte sociedad civil. ${ }^{3}$

Dicho en otras palabras es este profesionalismo el caldo de cultivo de las modernas empresas capitalistas exitosas. Estas nacen y se desarrollan en un medio de gran densidad de organizaciones sociales con actividades reglamentadas y que constituyen el capital social de una formación social. Algunas de éstas llegan a constituirse en lucrativas empresas poseedoras de una alta tecnología y eficaz organización laboral. Una situación similar a la europea occidental y norteamericana presentan algunas sociedades asiáticas con influencia confucionista que permitió un avanzado desarrollo de sus sociedades civiles en torno a la profesionalización de las artes y oficios. ${ }^{4}$ En estos casos estamos hablando de una cultura de la profesión basada en la adquisición y ejercicio de conocimientos y destrezas por parte de los miembros de una formación social o grupo social y que es la base de su desarrollo económico (aunque su origen como capital social no se encuentre exclusivamente en el nivel de las relaciones económicas).

La importancia de lo cultural sobre lo económico no reside sólo en el aspecto genético, en la explicación del origen de los fenómenos económicos, sino que tiene efectos permanentes en el ámbito de lo económico y constituye parte del 'capital social', entendido éste como la capacidad de los individuos de asociarse los unos con los otros. Este capital social que se define a nivel cultural es una fuerza productiva en su propio derecho. De acuerdo a F. Fukuyama, esta capacidad de los individuos de asociarse depende de las normas y valores que son compartidos por las comunidades, pero también de la disposición de los individuos a subordinar sus intereses a aquellos de grupos más amplios. De estos valores compartidos nace la confianza y la confianza tiene un valor económico importante y medible. ${ }^{5}$

\section{3. La profesionalización en América Latina}

En América Latina la profesionalización de la sociedad es, sin duda, menor: la debilidad de sus sociedades civiles y la aún gran importancia de los lazos familiares en las adscripciones de las personas es manifiesta. Incluso las empresas 'modernas' son de carácter familiar en su propiedad y paternalistas en sus relaciones laborales. Sin duda, en el presente hay una profesionalización creciente de las formaciones sociales de América Latina, pero vinculada fundamentalmente al desarrollo tecnológico en los países desarrollados e incorporadas estas nuevas profesiones en América Latina por medio de su rentabilidad económica (a través de la cual se procesa su utilidad social).

Como mencionan algunos dirigentes sindicales entrevistados por CEPAL (1995), el mismo proceso de modernización que experimenta América Latina va creando las necesidades de un trabajador más profesionalizado. ${ }^{6} \mathrm{La}$ calidad del producto ya establece estrictos requerimientos de producción con los que el trabajador debe cumplir. ${ }^{7}$ Algunos de los entrevistados, en esta

3 Por ejemplo, el Imperialismo Británico de la Era Victoriana que organizó profesionalmente desde la empresa capitalista moderna al comercio mundial, desde los Boy Scouts hasta el Ejército de Salvación. desde el fútbol asociado hasta los deportes invernales. Algunas de estas actividades orientadas al lucro. otras, de carácter benéfico. y' las más organizadas originariamente con carácter no lucrativo pero que luego dan origen a actividades lucrativas (en el caso de los deportes se mantienen estructuras paralelas "amateur" y profesionalesi.

4 M. Morishima: Why has Japan "Succeded"? Westem technology and the Japanese ethos; Cambridge University Press; 1984

5 F. Fukuyama: "La Confiance en la Pusissance: Vertus sociales et prospérité économique; PLON. 1996

6 Estudio realizado en seis empresas por cada uno de cinco países de América Latina (Argentina. Bolivia. Brasil, Chile y Ecuador). CEPAL. Imágenes Sociales de la Modernización y la Transformación Tecnológica"; Santiago de Chile de 1995

7 Uno de estos dirigentes sindicales menciona, por ejemplo. que: "La modemización no es exclusiva de los economistas, de los mievos empresarios, por lo menos tácitamente el trabajador también ha sido parte de esta moderniación. le entrega su espécialización al desarrollo de las distintas variedades y especies fruticolas. tal vez sin tomar conciencia de por qué y para qué se está especializando. Por ejemplo. los podadores son un aporte al desarollo teconológicosi a la modernización del país, si se hace mal la poda de los kiwis después har ain mal prodacto, lo mismo con el riego de las berries". 
investigación, destacan la disminución del esfuerzo físico. lo que. en algunos casos, perciben como la revalorización de la actividad intelectual y advierten una mayor independencia del trabajador del control del supervisor. Se advierte una may or valorización del trabajo como resultado de esta nueva relación entre el trabajador y máquinas caras y complejas (el valor de las máquinas se traspasa a quien tiene que operarlas). También se aprecia la eficiencia que se logra con las nuevas tecnologías. G. Labarca (1998), refiriéndose a los programas de formación de la industria automotriz mexicana, relaciona la capacitación con la independencia que el trabajador puede lograr en la realización de sus actividades laborales. Para ello los conocimientos de orden teórico ocupan un papel central. De lo que se trata es que el trabajador debe conocer bien todas las operaciones de su estación de trabajo y debe ser capaz de identificar los problemas atribuibles a sus operaciones, lo que también significa conocer el entorno de trabajo. Esto naturalmente resulta en una mayor independencia del trabajador con respecto a sus supervisores. ${ }^{8}$

Pero a diferencia de los países de Europa Occidental bajo influencia calvinista y los países de Asia con fuerte influencia confucionista, en América Latina la profesión no tendría la misma centralidad en la cultura (el desarrollo tecnológico no se origina en América Latina sino que se 'adapta'). Por lo pronto el carácter autoritario y jerárquico de la empresa con bajo desarrollo organizacional no se presta para la profesionalización de los trabajadores. Quizás sea este carácter autoritario de la empresa en América Latina que explicaría la particular forma de adopción de elementos de sistemas modernos de producción como el creciente énfasis en las remuneraciones variables sobre la remuneración fija y el mayor uso de contratos temporales y de la subcontratación. Estos no conducen a una mayor profesionalización. Entre estos elementos modernos también se encuentran otros factores que han sido recogidos por la reestructuración productiva en América Latina como son el aumento de la intensidad del trabajo y la extensión de la jomada que se unen a los tradicionales bajos niveles de remuneración y pobres condiciones laborales que tienen un carácter estructural.

\section{4. Adopción parcial de los modernos sistemas de producción en América Latina}

La proliferación de las nuevas tecnologias industriales a nivel mundial ha provocado la difusión de nuevos modelos de fabricación industrial con sistemas de producción flexibles, trabajo en equipos y suministro 'justo a tiempo'. El desarrollo de la Tecnología de Información ha hecho posible la comunicación interactiva entre los trabajadores a nivel de funciones y jerarquías. De acuerdo a R. Arnold (1998) en la actualidad hay una tendencia a la disminución del trabajo no calificado en los procesos productivos, en tanto el trabajador calificado debe ser capaz de autoorganizarse y de asumir responsabilidades en la planificación, ejecución y evaluación de las tareas profesionales y en que la profesionalidad se va redefiniendo en torno a competencias adquiridas con la experiencia de trabajo."

En otras palabras, las modernas relaciones de producción exigen un creciente y mas alto nivel de profesionalización del trabajo y por lo tanto de la capacidad de la sociedad para proveer las destrezas y calificaciones requeridas. La necesidad de organización y responsabilidad propia son parte constituyente de la vida profesional en su expresión más acabada.

8 G. Labarca: Formación para el trabajo en industras mexicanas: Proyecto Conjunto CEPAL/GTZ Políticas para mojorar la calidad. eficiencia y la relevancia del entrenamento profesional en América Latina y el Caribe" (FRG/96/S38): Santiago de Chile. 1998.

y R. Anold. "Cambios Tecrológicos y' Organizativos en la Formación Profesional": Proyecto Conjunto CEPAL/GTZ Políticas par Mejorar la Calidad. Efciencia y Rejerancia de la Edwación Ténica y al Entrenaniento de America Latina y el Caribe (FRG/96/S38): Santrago de Chite 1998. Cita de H. Wuber: Dic Evolution con Produktionspandigmen. In: ders. (Hrsg.): Lean Nanagemem Wige aus der Krise. Orgimbatorische un gesellschaftliche Suntegien. Wiesbaden 1994. S. $21-4 t$. 
Hasta comienzos de la década se suponía que en América Latina la adopción de prácticas modernas de producción 'toyotistas' por empresas de punta produciría un efecto dominó sobre el resto de las empresas lo que conllevaría un cambio generalizado de relaciones de producción. De acuerdo a R. Echeverría:

Independientemente de las diferencias culturales que tengamos con los japoneses.., las principales diferencias imolucradas son diferencias que resultan de dos 'sistemas' distintos de organización del trabajo. En este enfoque, cuando un trabajador (independientemente de sus antecedentes culturales) es puesto a trabajar al interior de este sistema de producción, funciona dentro de la 'lógica del sistema' y demuestra comportamientos y resultados equivalentes. Las diferencias culturales serian importantes sólo para explicar el origen de los sistemas de producción, pero una vez que estos se implementan sus resultados son comparables." ${ }^{\prime \prime}$

Sin embargo, esta expectativa ha estado lejos de cumplirse, las innovaciones introducidas efectivamente en las empresas, más que estimular la participación y creatividad de los trabajadores (que requiere esta profesionalización), buscan una utilización lo más eficiente posible tanto de la fuerza de trabajo disponible como de las nuevas máquinas y equipos. Lo que estaría ocurriendo es una incorporación parcial de elementos de las formas modernas de producción:

- Separación física de fases o procesos enteros de producción a otras plantas o creación de nuevas empresas; transferencia a terceros de la producción de insumos y de la prestación de servicios (que acompaña a la generalización de la subcontratación como medio de acceso a éstos por parte de las empresas); y subcontratación del suministro de fuerza de trabajo.

- Con respecto al proceso de trabajo se trata de lograr un aumento en la intensidad do trabajo en las empresas; extensión de la jornada de trabajo; cambios en las formas de contratación de la fuerza de trabajo (permitiendo mayor flexibilidad a la empresa y disminución de los costcs de administración y de empleo).

Sin embargo, en América Latina la incorporación de formas modernas de producción no: parece dirigida al desarrollo de los recursos humanos. Una tendencia importante, más bien es intentar disminuir el factor de incertidumbre del recurso humano en el proceso de producción. Finalmente. la capacitación que se realiza está dirigida principalmente a los estamenic. administrativos y profesionales.

De acuerdo a G. Salazar (1997) la dependencia tecnológica externa es la que determiná atraso del sistema de capacitación y educacional:

La inversión de capitales en la compra de tecnología se contrapone y anula la inversión en Investigación y Desarrollo, pues la primera fortalece de hecho la pasividad que la segunda, por principio, necesita abolir. Mientras se siga privilegiando esa compra y mientras la innovación tecnológica siga siendo para el pais una función mercantil-importadora, el sistema educacional y capacitacional estará siempre retrasado y será siempre inadecuado para cubrir las necesidades productivas estratégicas de las (grandes) empresas.".

10 R. Echeverría; "Notas sobre el mundo empresarial de hoy"; PREALC N³74; Marzo de 1993

11 G. Salazar; Capacitación, compecitividad e innovación tecnológica en Chile (1976-1997); Proyecto Conjunto CEPAL/GT?

"Políticas para mejorar la calidad y la relevancia del entrenamiento profesional en América Latina y el Caribe" FRG/96/538;

Santiago de Chile 1997. 
No obstante que la disponibilidad de tecnología en el exterior es un disuasivo a la inversión en investigación y desarrollo, aquí se sostiene que es la debilidad de la organización social y de la consiguiente profesionalización la que determinaría finalmente la dependencia tecnológica.

Se asume que la fuerza de la economía, más allá de la densidad y desarrollo de las organizaciones económicas que se posean. depende de la profusión de organizaciones de la sociedad civil a la que el concepto de profesión se relaciona. Desde luego que el carácter marginal de la profesión en la cultura en América Latina se refleja en la pobreza de sus sociedades civiles carentes de manifestaciones organizadas de los intereses diversos de su población.

Lo que la reseña hecha aquí nos está indicando es una posible divergencia entre el éthos requerido por las relaciones económicas modernas y los éthos imperantes en la sociedad. La adopción, adaptación y por lo tanto la eficacia de estos sistemas está condicionada por los éthos existentes en la sociedad.

\subsection{Las relaciones de producción capitalistas son compatibles con una diversidad de éthos}

En Chile la política de empleo aplicada por las empresas se centra en la prescindibilidad del personal con respecto a la composición de capital requerida para responder a las demandas del mercado en la coyuntura. La ley (artículo 161, inciso primero del Código del Trabajo) permite que la empresa expeditamente prescinda de sus trabajadores por 'necesidades de empresa'. De acuerdo a ENCLA 98, esta causal alcanza a explicar un $14.7 \%$ de los términos de contrato, en tanto, el 'término de plazo' alcanza a un $50.1 \%$ y la 'renuncia voluntaria' un $26.1 \%$ de éstos. ${ }^{12}$

Asumir este carácter prescindible del recurso humano en la empresa es parte de un éthos empresarial y no corresponde a una necesariedad de sobrevivencia y expansión de la empresa. R. Arnold (op. cit. 1998) citando a H. Weber (1994) menciona que:

'La política de empleo aplicada en Japón, no se centra en la intercambiabilidad del personal y en la adaptación de la suma de los sueldos y salarios pagados a las oscilaciones que presenta la coyuntura (reduciendo el personal cuando sea necesario), sino que más bien sucede lo contrario: todos los mecanismos organizativos aplicados, por ejemplo, en la investigación y el desarrollo, en la fabricación y en ventas, tienen la finalidad de asegurar la subsistencia de los contratos laborales y los puestos de trabajo'. (R. Arnold op. cit. 1998)

Es decir, en el marco de las mismas relaciones de producción, las mismas desde el punto de vista de las relaciones de propiedad sobre los medios de producción y de las consecuentes relaciones de mercado, se pueden encontrar muy distintas orientaciones empresariales. Estas orientaciones tienen efectos decisivos sobre la estabilidad de empleo, remuneraciones, extensión de la jornada de trabajo, la capacitación y participación de los trabajadores en la empresa.

En Chile, las políticas de empresa en el corto plazo a menudo buscan a través de las remuneraciones, de la flexibilidad de los contratos de trabajo, de la extensión de las jornadas de trabajo y de las políticas de capacitación, aumentar la competitividad. El trabajador básicamente está sujeto a la política de la empresa en términos de empleabilidad y de remuneraciones. Para muchas empresas se trata de obtener el máximo de productividad del trabajador al menor costo,

12 ENCLA98: Encuesta Laboral: Infome Ejecutivo: Departanento de Estudios. Dirección del Trabajo: Noviembre de 1998. 
pero a cambio de incrementar la penuria del trabajador, de limitar sus expectativas en general y sus aspiraciones de capacitación en particular. Las opciones del trabajador se reducen a aquellas relativas a la mantención del empleo y de sus ingresos, pero dificulta su proyección de empleabilidad, de remuneraciones, de formación profesional a futuro. Veremos que esta lógica tiene serios efectos en términos de conformar un éthos laboral.

\section{6. La centralidad de la Cultura en el análisis}

La tecnología que se adopte será siempre en un medio social y cultural dado. El desarrollo y adaptación de tecnología no se da en un vacío social y cultural. Como mencionan M. Baba, et al. (1997):

'En tanto que indudablemente la tecnología tiene la capacidad de permitir el vínculo en un sentido físico o electrónico, nuestro problema real no estriba en el reino físico, sino en los reinos social y cultural. En nuestra opinión, la meta del cambio de procesos no es simplemente la integración (que puede lograrse mediante la tecnología), sino la cooperación (que puede lograrse únicamente a través de las personas). Los procesos comerciales conectan a las personas, y cualquier tecnología que intente permitir conexiones entre ellas estará sujeta a las reglas culturales que la gente crea para orientar y regir sus intenciones.'."

A nivel de cada empresa la tecnología tendrá que dar cuenta de la cultura corporativa existente. Esta cultura corporativa es el resultado de su historia específica y refleja una combinación particular de valores culturales nacionales. Estos últimos (los valores culturales nacionales) son determinantes y configuran una homogeneidad de actitud de parte de las empresas. ${ }^{H+}$ En ese plano podemos hablar de éthos empresariales y laborales que condicionarán la incorporación de tecnología, la organización del trabajo, las relaciones con proveedores y clientes, la política de capacitación y formación profesional, etc.

En este documento se intentará dar cuenta de los valores empresariales y laborales en su efecto sobre la capacitación y formación profesional a nivel de la empresa. El énfasis no va a estar puesto en los valores corporativos o de trabajo, sino en aquellos de carácter nacional en su manifestación a nivel de las empresas. La referencia para éstos será el caso de Chile, pero, también se asume que estos valores son compartidos en mayor o menor medida por el resto de los países latinoamericanos. ${ }^{15}$

\section{PREGUNTAS CENTRALES FRENTE AL TEMA}

El desarrollo de la hipótesis de trabajo de que la profesión no tendría la misma centralidad en la cultura que en los países calvinistas o confucionistas requeriría establecer en forma comparativa el relativo subdesarrollo de la organización social en América Latina con respecto a estas otras formaciones sociales; además requeriría la revisión de la evolución de los cuerpos culturales centrales de la sociedad

13 M. Baba. D. Falkenburg. D. Hill: Cap. IX Cambio Empresarial: Dimensiones Culturales de las Nuevas Tecnologías; Innovación Tecnológica y Procesos Culturales: M. J. Santos. R. Díaz Cruz (eds.): Ediciones Científicas Universitarias: Horizontes y Paradigmas en Ciencia y Tecnología: UNA; Fondo de Cultura Económica; México, 1997.

14 En las investigaciones de Baba et. al, surgen algunos ejemplos interesantes: el individualismo norteamericano que se expresa en la búsqueda de autonomía de las unidades organizacionales puede dificultar el desarrollo de trabajo en equipo a nivel de la empresa y la integración de procesos que permite la Tecnología de Información. Por otra parte, paradojalmente la fe norteamericana en la tecnología hace muchas veces dificil identificar las barreras culturales y sociales existentes en las empresas para la integración de procesos. (M. Baba. et al.op.cit.1998)

15 La particular importancia de la cultura nacional frente a la corporativa o de trabajo reside en que es en ésta que nacimos (genera nuestras primeras identidades, sentimientos de pertenencia y adhesión a valores del colectivo más amplio al que pertenecemos) y las otras (corporativa y de trabajo) las adquirimos en nuestro desarrollo profesional y ocupacional y reflejan y se articulan como subculturas a los valores ya adquiridos. 
para establecer el porqué de este subdesarrollo. Indudablemente esta investigación escapa del todo a los objetivos propuestos para este documento. Sin embargo, queda abierta la alternativa de explorar a nivel de las relaciones económicas la importancia otorgada a la profesionalización por los agentes económicos. Dos indicadores muy centrales a ésta son sin duda la importancia otorgada por éstos a la capacitación y a la participación: la capacitación en la medida que implica que el trabajador realiza mejor su trabajo; y la participación en la medida que significa que el trabajador asume más responsabilidades y autodeterminación. Ambos. valores centrales a la actividad profesional.

La profesionalización de la sociedad debiera resultar en una descentralización en la toma de decisiones. Efectivamente, el 'especialista' o 'experto' debiera ser el más idóneo para asumir responsabilidades y tomar decisiones en el ámbito de su campo de trabajo. Sin embargo, en el caso de Chile la confianza en el trabajador como profesional parece ser reducida. Como veremos en el transcurso de este documento los empresarios se verían a sí mismos como protagonistas y manifiestan una tendencia a centralizar en sí mismos todas las decisiones. De acuerdo a G. Salazar (op. cit. 1998), los empresarios tienden a definir el espíritu empresarial y el liderazgo económico como parte de una acción privada y exclusiva de ellos mismos. El tema de capacidad de liderazgo y carisma parecen ser centrales a la imagen que los empresarios tienen de sí mismos. También veremos que los empresarios. de acuerdo a los trabajadores. parecen poco motivados a entregar capacitación y participación a los trabajadores y confían más en la adquisición de máquinas que en el desarrollo de sus recursos humanos y por fin, que los mismos trabajadores se ven a sí mismos poco motivados para capacitarse.

Pero lo pertinente de preguntarse sobre el lugar de la profesión en la sociedad en América Latina -para los objetivos del presente trabajo- reside en plantearse cómo generar una demanda de capacitación en la población que siquiera pueda aprovechar las oportunidades de capacitación y formación profesional que la sociedad ofrece. Aquí se sostiene que más allá de la ineficacia e insuficiencias de la oferta de capacitación en América Latina, ésta se enfrenta a una demanda definida culturalmente. La pregunta que habria que hacerse es qué obstáculos culturales impiden la formación de una demanda para la capacitación por parte de la población trabajadora y los empresarios.

La aspiración por capacitación y por la formación profesional dependerá de una multiplicidad de factores culturales interrelacionados, entre otros: de las expectativas de progreso que tengan los trabajadores; de su propia valoración del trabajo y de la valoración de los empleadores; de su identificación con la fuente laboral; de la percepción de la relación con sus empleadores y la de éstos con sus trabajadores. Es decil; la aspiración y las expectativas de capacitación y desarrollo profesional son un factor integral tanto del éthos laboral como empresarial, es parte de la cultura laboral.

Aquí se asume, por un lado, que la modernización económica es compatible con una diversidad de éthos, por otro lado, que sin embargo, un sistema económico vería limitado su desarrollo si la gente posee un éthos 'divergente' de las relaciones económicas que se implanten. ${ }^{16}$ Finalmente, pequeñas diferencias de éthos resultan en profundas diferencias en el desarrollo económico. Este efecto distinto de diferencias culturales marginales sobre lo económico ya había sido establecido tentativamente por Weber en su análisis del concepto del trabajo y la profesión en el catolicismo. luteranismo y calvinismo. En Weber el espíritu del capitalismo está vinculado genéticamente principalmente a la ideología calvinista. ${ }^{17}$ También M. Morishima (op. cit.) hace

16 El entoque del éthos laboral que se realiza en esta investigación es a partir de preguntas sobre su adecuación a determinadas relaciones de producción, y no contempla un concepto de éthos como respuesta alternativa a las relaciones de producción existentes o más aún conn estrategia de vida de los trabajadures. Esto requeriría la realización de investigación adicional a la contemplada aquí.

17 Por éthos se entenderá la jerarquía de valore con respecto a los cuales los agentes sociales conforman su conducta. Por éthos laboral se entenderá la paticular jerarquia de salores con respecto a los cuales los trabajadores conforman su conducta profesional. 
el mismo caso para Japón con respecto a China, en que una particular adopción del Confucionismo y Taoísmo chino por parte de Japón hizo posible una exitosa adopción de tecnología occidental.

Una política de capacitación y formación profesional no se realiza en un vacío social sino que ha de considerar las características de la cultura, el medio social y de las condiciones materiales de trabajo. Es obvio que la capacitación es importante tanto para las empresas como para los trabajadores: por un lado, la capacitación lleva a un aumento de productividad; por el otro, posiciona mejor al trabajador al interior de su empresa y en el mercado de trabajo. De allí que es de esperarse que tanto empleadores y trabajadores le asignen una alta importancia a la capacitación. Pero esta expectativa resulta ser más la excepción que la regla: los antecedentes muestran que esta importancia de la capacitación no se expresa necesariamente en un interés efectivo y manifiesto en ella por parte de los agentes económicos. El asunto es que las imágenes sociales sobre capacitación no pueden considerarse con abstracción, entre otros, de los siguientes factores: la percepción del empleado del tipo de trabajo que éste desempeña; de su sensación de ser o no recompensado adecuadamente por éste; del reconocimiento social de su labor; de las expectativas a futuro que le entrega su empleo; de su percepción de la calidad de relación que tenga con el empleador; etc. Estos determinarán en gran parte las aspiraciones de capacitación del trabajador.

- Para efectos de cualquier política de formación profesional y capacitación cabría preguntarse si los trabajadores están interesados o no en capacitarse y si los empresarios están interesados efectivamente en que sus trabajadores se capaciten.

- Esta pregunta nos lleva a otras relativas a las condiciones laborales y de empleo de los trabajadores. Desde luego, en la medida que el trabajo no es valorado, tampoco lo será la capacitación respectiva. La capacitación consiste en que los trabajadores realicen en mejor forma su trabajo pero, acaso ¿son valorados estos trabajos por los trabajadores, los empleadores y la sociedad en general?

- En la medida que los trabajadores perciban que sus esfuerzos en capacitarse no son recompensados con mejores condiciones laborales y mayores ingresos no es de esperarse que busquen mejorarla. Con respecto a esto cabe preguntarse: ¿tienen los trabajadores las expectativas de progreso que se requieren para sí mismos y sus familias para invertir tiempo y dinero en ésta? Esta hipótesis es controversial, ya que puede argumentarse que en ausencia de un 'ethos profesional' la amenaza de mayor precariedad de condiciones de trabajo y remuneraciones también es un estímulo para que los trabajadores requieran capacitarse. El respaldo a la posición sostenida aquí es conferida por las respuestas de dirigentes sindicales entrevistados.

- Los trabajadores no se interesarán en la capacitación de carácter específica ('capacitación en el trabajo') que es de interés directo para las empresas a menos que se perciba la posibilidad de una carrera al interior de la empresa. Con respecto a esto cabría preguntarse: ¿tienen interés los trabajadores en identificarse y acaso participar en las empresas en que trabajan?; ¿tienen los empleadores interés en que los trabajadores se identifiquen con las empresas en que trabajan?

Las respuestas a estas preguntas nos permiten configurar un éthos laboral que constituye la matriz cultural en la que se inserta cualquier política de capacitación y formación profesional. Es con respecto a estos valores culturales que una política de capacitación y formación profesional aparecerá como más o menos eficaz.

La importancia que los trabajadores le asignen a la capacitación estará en función de su 
percepción de pertenencia al sistema de relaciones sociales en que está inserto y su sensación de bienestar. Aquí se asume que un trabajador que posea un éthos adecuado a las relaciones económicas que existan en un momento dado, tendrá una mayor productividad y. más allá de su empresa, se posicionará mejor en el mercado de trabajo con los consiguientes beneficios a futuro para sí mismo y su familia (D. Burnett. ACHV. 1998)."

Un trabajador tendrá un éthos adecuado al desarrollo en la medida que:

- Valore su trabajo.

- Obtenga el reconocimiento de sus empleadores y otros trabajadores.

- Manifieste interés en la participación en su empresa (que incrementará la pertenencia del trabajador a la empresa y a otras instancias orgánicas).

- Tenga expectativas de progreso para él y los suyos.

- Tenga una actitud positiva con respecto a la capacitación (que significa aumentar su capacidad de trabajo).

Un éthos laboral que priorice estos valores tendrá que tener como contraparte un éthos empresarial que valore el trabajo y que por lo tanto reconozca efectivamente la contribución de sus empleados, permita el desarrollo de la capacitación y participación de los trabajadores en la empresa y que asegure la condiciones de trabajo y remuneración que posibiliten a los trabajadores tener altas expectativas de progreso para sí mismos y su familia.

Estos factores conforman un éthos de trabajo adecuado para el progreso económico, a nivel personal y social. Por otra parte, las 'carencias' con respecto a estas actitudes esperadas pueden impedir la adecuada incorporación del trabajador al proceso económico.

Finalmente. la necesidad de considerar la capacitación en relación a otros factores sociales está dada por las demandas mismas que las empresas formulan. En Volkswagen de Puebla, se encontró que aproximadamente el $80 \%$ de los problemas de falta de eficiencia, que no dependen del tipo de maquinarias e instrumentos de uso. son resultado de problemas relacionados con el 'clima de trabajo' y sólo un $20 \%$ se deben a deficiencias de capacitación. (G. Labarca, op. cit.. 1998).

\section{CARACTERIZACIÓN DEL ÉTHOS LABORAL EN CHILE}

\section{1. Bajas expectativas}

Un factor que se ha estimado importante para definir un éthos es el nivel de expectativas de las personas y de lo que las personas están dispuestas a hacer para su logro. Es de esperar que de acuerdo a las prioridades de interés (necesidades) de los trabajadores éstos adecuarán los medios a su disposición para su realización. En la sociedad el nivel de expectativas funcionaría como una 'fuera productiva'. A continuación veremos las aspiraciones de los estratos socio-

18 En junio de 1998 con ocasión de la realización de dos escileb sindicales para dirigentes nacionales de la industria del plásico y de dirigentes de base de técnicos ? profesionales de Correos de Chile respectivamente rrentada por la

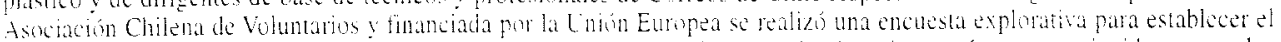

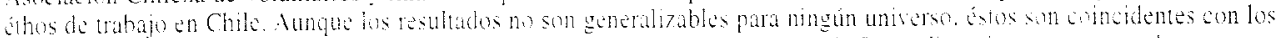

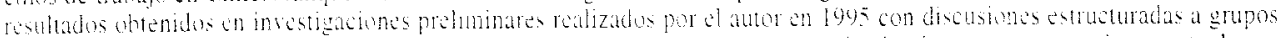

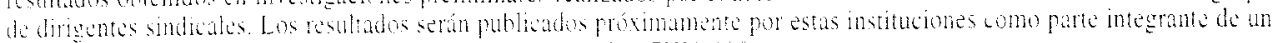

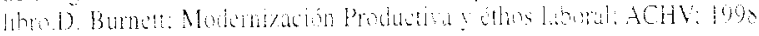


económicos alto, medio y bajo, de acuerdo al Estudio Nacional de Opinión Pública DESUCCOPESA de noviembre de 1995, para luego comparar éstas con aquellas que son procesadas en las negociaciones colectivas en el lugar de trabajo. ${ }^{19}$ Aparentemente no habría una 'correspondencia' entre las expectativas establecidas a nivel del consumo con las procesadas en el lugar de trabajo.

\section{1. 1. A nivel del consumo}

Una primera aproximación a las aspiraciones de los trabajadores puede realizarse a partir de los resultados que proporciona el Estudio Nacional de Opinión Pública, DESUC-COPESA de noviembre de 1995. Este estudio que distingue entre estratos socioeconómicos nos entrega una imagen de las aspiraciones de la población de los principales centros urbanos del país. ${ }^{20}$ En esta investigación se preguntó a los encuestados qué cosas les gustaría hacer si tuviesen más ingreso (con un máximo de tres menciones): un $42.3 \%$ de los encuestados de nivel socioeconómico bajo mencionaron mejor colegio; le siguió en orden de preferencias, comprar casa $(42.3 \%)$; mejor plan de salud (38.6\%); arreglar casa (28.9\%); y mejor educación (25.1\%)

Para el grupo de nivel socioeconómico medio, las opciones más mencionadas fueron: mejor colegio $(32.9 \%)$; mejor plan de salud (31.5\%); comprar casa $(31.1 \%)$; viajar $(27.6 \%)$; y estudios $(26.2 \%)$.

El patrón de respuestas difiere sustancialmente para el grupo de nivel socioeconómico alto. Para éste, la primera opción fue viajar $(68.6 \%)$; a la que siguieron casa de veraneo (25\%); mejor plan de salud $(23.1 \%)$; mejores vacaciones $(21.6 \%)$; y comprar mejor casa $(17.7 \%)$.

En el estrato alto las aspiraciones son al consumo suntuario en tanto en los estratos medios y bajos las aspiraciones son al mejoramiento de condiciones de vida. En el estrato medio (cuyo nivel ocupacional tendería a corresponder con el técnico-profesional de nivel medio, el obrero especializado, el empleado público y privado, el pequeño industrial y el comerciante) con frecuencia se menciona a 'estudios' entre las 'cosas' que el encuestado le gustaría hacer si tuviese más ingreso. ${ }^{21}$ La prioridad por 'mejor colegio', tanto en los estratos medio como bajo, se vincularía con la necesidad de fortalecer la posición de las nuevas generaciones en el mercado de trabajo y de acceder a la movilidad social. ${ }^{22}$

En el mismo estudio se informa que un $42.5 \%$ de los entrevistados de estrato bajo piensa que sus expectativas de situación económica futura son buenas o muy buenas. Estos porcentajes suben a $60.8 \%$ y $85.6 \%$ respectivamente para los estratos medio y alto. Es decir, una alta proporción de los encuestados piensa que efectivamente es posible lograr las aspiraciones mencionadas arriba. Desde luego, para los estratos bajos -que en una proporción ligeramente mayoritaria piensa que su situación futura es regular, mala o muy mala- esta inferencia sólo es parcialmente válida. Para

19 Entre octubre y noviembre de 1995 se realizó una encuesta en los principales centros urbanos de Chile y la muestra fue de 2.041 casos. El informe de esta investigación se encuentrá en: Dirección de Estudios Sociológicos Pontificia Universidad Católica de Chile (DESUC). Consorcio Periodistico de Chile S.A. (COPESA): Estudio Nacional de Opinión Pública: Noviembre de 1995 .

20 En término de categorías ocupacionales en el estrato alto esperariamos encontrar a profesionales. empresarios, comerciantes. En el estrato medio. profesionales y técnicos de nivel medio. obreros especializados. comerciantes. artesanos. pequeños industriales. empleados públicos y privados. En el estrato bajo esperaríamos encontrar obreros trabajadores manuales y también empleados privados y públicos de bajo nivel.

21 Más adelante el punto 2. principalmente sobre el análisis de los antecedentes entregados en la tabla $N^{\circ} 3$ se refiere a la distribución de la capacitación entre los estratos ocupacionales.

22 Ver:E. Faletto; "Panorama Social": Análisis del Año 1998: Sociedad-política-economía; Departamento de Sociología Universidad de Chile: 1999. 
estos sectores sus necesidades de mejorar sus condiciones de vida son fuertes, pero sus expectativas, para una mayoría de ellos serían menores que para los miembros de los otros estratos.

\section{1. 2. En el lugar de trabajo}

La Dirección del Trabajo. sobre la base de los antecedentes obtenidos del análisis de las negociaciones colectivas de Chile durante 1995. constata que en la negociación colectiva (excluidos los reajustes de sueldos), las materias más frecuentes corresponden a beneficios en dineros esporádicos (aguinaldos y asignaciones): a resarcir algunos gastos directamente relacionados con la prestación de servicios (movilización y colación); en tanto aquellas que tienden a regular condiciones de trabajo, o a beneficiar el sueldo de los trabajadores con parte de los resultados del trabajo o mejorar su capacitación laboral (gratificación convencional. incentivos y bonos y capacitación) se encuentran entre las materias menos frecuentes en las negociaciones colectivas. ${ }^{23}$

Tabla $\Gamma^{\text {to }}$ 1: Frecuencia de incorporación de diversas materias a la negociación colectiva en Chile 1994-1995

\begin{tabular}{lc}
\hline Matcrias incluidas en la negociación colectiva & Porcentaje de negociaciones colectivas que incluyeron la materia \\
\hline Aguinaldo de Navidad & $76.5 \%$ \\
Aguinaldo de fiestas patrias & $73.5 \%$ \\
Movilización & $70.9 \%$ \\
Asignación de escolaridad & $60.6 \%$ \\
Colación & $58.0 \%$ \\
Asignación natalidad & $51.8 \%$ \\
Indemnización convencional & $34.2 \%$ \\
Pago de licencias médicas & $33.1 \%$ \\
Gratificación convencional & $31.5 \%$ \\
Incentivos y bonos & $31.1 \%$ \\
Paseo anual & $19.5 \%$ \\
Pageo permiso sindical & $14.2 \%$ \\
Asignación antigüedad/mes & $10.2 \%$ \\
Capacitación & $19.3 \%$
\end{tabular}

Fuente: Dirección del Trabajo; Departamento de Negociación Colectiva

Estos antecedentes sugieren que los trabajadores intentan a través de sus instrumentos de negociación colectiva fortalecer su posición en el mercado para optimizar sus recursos (en el logro de las aspiraciones mencionadas arriba) pero sin comprometerse con la empresa, ni siquiera en lo que se refiere a su propia capacitación. Estos datos, también sugieren. como veremos más adelante, que los incentivos a la productividad, más que una aspiración de los trabajadores, son parte de una estrategia empresarial para aumentar la intensidad del trabajo y la extensión de la jornada de trabajo.

Desde luego que esto se debe en parte a la debilidad de la organización sindical y al poco poder de negociación de los trabajadores. De acuerdo a la Dirección del Trabajo y al Programa de Economía del Trabajo (citados). la negociación colectiva poco regula las condiciones de trabajo, en tanto los beneficios adicionales que se presentan en las negociaciones tampoco tienen una may or incidencia en el mejoramiento de las condiciones de vida de los trabajadores que negocian. En resumen. la negociación colectiva no sólo es ineficaz para la obtención de reajustes salariales

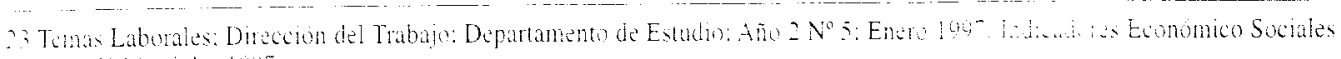

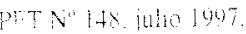


(que al menos debiera corresponder a los incrementos en productividad de las empresas en que se negocia), sino que no incluye materias que significarían un mejoramiento sustantivo de las condiciones de trabajo, incentivos para aumentar la productividad ni desarrollo de los trabajadores.

Se puede concluir que los trabajadores, a través de los mecanismos de negociación colectiva obtienen no necesariamente lo que desean sino lo que es factible obtener del empleador. El procesamiento de las demandas de los trabajadores en la negociación colectiva resulta en un deterioro de sus propias aspiraciones en un contexto de alienación de la empresa (que, entre otros se manifiesta en el no compromiso con la capacitación y participación). En este sentido las relaciones entre empleadores y empleados ponen un límite a las expectativas de los trabajadores para su desarrollo. Esto es de gran importancia pues indica que los trabajadores sustraen del empleo su voluntad de hacer que la empresa progrese y que ellos mismos se desarrollen como trabajadores y personas. Este deterioro de expectativas de los trabajadores se relaciona a la estrategia empresarial mencionada arriba de supeditar a los trabajadores a la competitividad de la empresa en lo que respecta a remuneraciones y empleabilidad.

En el estudio exploratorio realizado en Junio de 1998 a dirigentes sindicales de Correos de Chile y de la industria del plástico (D. Burnett, ACHV, 1998) una mayoría de los dirigentes opinaron que los trabajadores no tienen altas expectativas de progreso para sí mismos y su familia. Los dirigentes sindicales fundamentaron estas respuestas en la falta de oportunidades de capacitación de los trabajadores; las bajas remuneraciones; la inestabilidad ocupacional y la eventualidad de la subcontratación; relativo a la falta de desarrollo organizacional de las empresas, la carencia de una carrera funcionaria y la existencia de favoritismos que no permiten tener una visión de progreso. Este patrón de respuestas es bastante importante en términos de conformar un éthos laboral. (D. Burnett, op. cit. 1998). En nuestra hipótesis, bajas expectativas conforman una actitud de acomodar esfuerzo y medios a logros limitados.

\section{2. Pobre motivación para capacitarse}

Los trabajadores parecieran no estar interesados en la capacitación. De acuerdo a los datos entregados por la Dirección del Trabajo sólo en un 19.3\% de las negociaciones colectivas entre los años 1994 y 1995 se incluyeron a la capacitación como materia de negociación. La importancia otorgada por los propios trabajadores a la capacitación es bastante baja si la comparamos con la inclusión de temas como aguinaldo de Navidad en $76.5 \%$ de las negociaciones colectivas, aguinaldo de fiestas patrias $73.5 \%$, movilización $70.9 \%$, asignación de escolaridad $60.6 \%$, colación $56 \%$, asignación natalidad $51.8 \%$, indemnización convencional $34.2 \%$, pago de licencias médicas $33.1 \%$, gratificación convencional $31.5 \%$, incentivos y bonos $31.1 \%$ y paseo anual $19.5 \% .^{24}$ Desde luego que en la medida que los trabajadores no perciban a la capacitación como un medio de movilidad social no la priorizarán en sus petitorios. De acuerdo al SENCE, un trabajador chileno se capacita cada siete años, en comparación con los países desarrollados, donde lo hace cada dos a tres años.

Sin duda, que entre las causas de la falta de interés por parte de los trabajadores en la capacitación se encuentran la normativa vigente que destina los recursos financieros disponibles para capacitación a los empresarios y no a los trabajadores, y que la capacitación se realiza en función de los requerimientos de aumento de productividad de la empresa y no de mejorar las oportunidades de empleo del trabajador. Si esto fuese cierto se estaría evidenciando una 'alienación'

24 Indicadores Económico Sociales PET No 148 Julio 1997. Temas Laborales: Año 2. No 5. Enero 1997 (Cit). 
del trabajador con respecto al destino de su empresa. Pero más importante que la particular inadecuación de las políticas de capacitación del Estado o de las empresas, es la situación de precariedad generalizada de la fuerza de trabajo a la que nos hemos referido y que desincentiva las aspiraciones de capacitación de los trabajadores.

Las expectativas de movilidad social de los trabajadores se refieren principalmente a las generaciones de reemplazo. Esto se reflejaría en la prioridad de gasto entregada al 'colegio' por los estratos socioeconómicos medios y bajos referida en el estudio de opinión DESUC-COPESA citada arriba.

También la creciente demanda de capacitación en administración, comercio y finanzas estaría reflejando un patrón de prioridades de los trabajadores de cuello azul para acceder a los estamentos administrativos y técnico profesional mejor posicionados en la Empresa.

En el estudio encargado por la Asociación Chilena de Voluntarios a dirigentes sindicales, aquellos que opinaron que los trabajadores tienen una baja motivación para incorporarse a cursos de capacitación, justificaron su respuesta argumentando que la capacitación no es reconocida en la evaluación del trabajador y en la determinación de las remuneraciones y condiciones de trabajo. Algunos dirigentes sindicales también opinan que muchos de los cursos son inadecuados, sus contenidos no pueden ser llevados luego a la práctica (se dice que son muy teóricos), o no contemplan las necesidades de capacitación de la empresa (se dice que están concebidos para otra realidad). También algunos dirigentes sindicales opinan que los trabajadores mismos no entienden la importancia de la capacitación y que los bajos sueldos imposibilitarían el acceso a ésta.

Los dirigentes de la industria del plástico, que representan a trabajadores de cuello azul. enfatizan más la supuesta escasez de alternativas de capacitación o que la empresa les niega esta posibilidad. A lo más. ésta es selectiva y dirigida a la administración y a aquellos que son elegidos para acceder a los cursos. A su vez, se argumenta que las propias condiciones de trabajo no permiten que el trabajador se capacite. lo que supone que la empresa no entrega la oportunidad durante la jornada de trabajo y que la capacitación es de un alto costo con respecto a su nivel de ingresos. Por último -y en esto coinciden con respuestas entregadas por dirigentes de Correoslos propios trabajadores no entenderían la importancia de la capacitación para su desarrollo.

La imposibilidad de obtener reconocimiento y mejores remuneraciones, debido a inexistencia de carrera funcionaria en las empresas inhibiría la motivación para capacitarse de los trabajadores. Los trabajadores mencionaron que en Chile los empleadores no delegan, más bien intentan realizar todas las tareas de responsabilidad ellos mismos. Además, el acceso a cargos de responsabilidad es reservado para el estrato administrativo, al que, por lo tanto, se le otorgan mayores posibilidades de capacitación. Se menciona que los ascensos no se realizan de acuerdo a criterios establecidos de funciones y capacidades requeridas. sino que a través del compadrazgo. En ese sentido, la falta de un desarrollo organizacional de la empresa funciona como un freno a las motivaciones de capacitación de los trabajadores.

Como se puede apreciar algunos de estos argumentos plantean:

- Son los propios trabajadores los que no tienen conciencia de la importancia de la capacitación o desconocen las oportunidades que en este campo tienen disponibles.

- Otras respuestas se refieren más bien a la calidad misma de la capacitación. Se argumenti. 
que no es de buena calidad, lo que entrega no está adecuadamente enfocado en el usuario, o simplemente no se entrega capacitación.

- Con respecto a las condiciones de trabajo se argumenta que las jornadas de trabajo son tan largas -producto de la necesidad del trabajador de incrementar sus ingresos- que el trabajador no tiene tiempo ni energía para participar en esquemas de capacitación. Es decir la empresa tampoco entregaría la posibilidad de capacitación como parte de la jornada de trabajo.

- Una proporción alta de respuestas se refiere a causas que se originan en las empresas mismas y que explican la baja motivación de los trabajadores por capacitarse: éstas no la entregan; la selección de los favorecidos es arbitraria y discriminatoria a favor del personal de administración (esto mismo, incluso, es planteado como un anhelo de los obreros de resultar objeto de los esquemas de capacitación al igual que el personal administrativo y de gerencia); la capacitación entregada no es tomada en cuenta en la evaluación de los trabajadores ni tiene compensación en las remuneraciones.

- De los que contestaron que los empresarios no están motivados para entregar capacitación a sus trabajadores, una mayoría fundamentó su respuesta principalmente en que a la empresa no le interesa la capacitación de los trabajadores. Ésta no tendría para qué capacitarlos. Para algunos, la propia oferta en el mercado laboral de trabajadores altamente calificados hace que el empresario considere innecesario capacitar. Otros aducen que la utilización de la franquicia tributaria otorgada a través del SENCE sería el único aliciente que la empresa tendría para entregar oportunidades de capacitación a los trabajadores. Aún más, de acuerdo a éstos las empresas ni siquiera utilizan la franquicia tributaria otorgada a través del SENCE.

- En fin, se argumenta también que el empresario es reticente a capacitar a sus trabajadores y que incluso prefiere que el trabajador permanezca en la ignorancia. Según algunos encuestados, en la percepción del empresario la capacitación constituye un puro gasto.

- Aunque con menor frecuencia, algunos dirigentes mencionaron que el empresario es reticente a capacitar dado el efecto de la capacitación en el nivel de remuneraciones. También, pareciera, que en la percepción de estos dirigentes sindicales, los empresarios temerían el efecto de la mayor capacitación en las remuneraciones y la imposibilidad de evitar la migración de los trabajadores. Este trabajador, capacitado, estaría en mejor posición para obtener mayores ingresos y mejores condiciones de trabajo en el mercado laboral. Esto haría difícil al empresario mantenerlo quizás realizando el mismo trabajo en la empresa.

- Entre aquellos dirigentes sindicales de Correos, que opinan que en Chile los empresarios están cada vez más motivados para entregar capacitación a sus trabajadores -o que siempre lo han estado- éstos fundamentan su respuesta en las propias necesidades de la empresa, resultantes de la apertura al comercio internacional, la creciente competencia, los desarrollos tecnológicos que se requiere incorporar para poder sostenerse en un mercado cada vez más exigente y al ejemplo de los países desarrollados.

\section{3. Desmotivación para participar}

En la encuesta de SERCOTEC a la pequeña y mediana industria chilena se encontró una visión de modernización compartida por empleados y empleadores en que ésta es entendida básicamente como de incorporación de nueva maquinaria y tecnología (visión tecnocrática). No 
existiría en el rango de estas industrias una visión 'integral' de empresa que comprenda una valoración del desarrollo de recursos humanos como componente de esta modernidad. También se encontró, que aunque prima una visión de cooperación entre empleados y empleadores, ésta aún se enmarca en un patrón paternalista de relaciones laborales. es decir. en relaciones de carácter más personal que de trabajo."

En la encuesta a los dirigentes sindicales de Correos de Chile y de la Confederación Nacional de Trabajadores del Plástico (1998. op. cit.) se encontró que, frente a la participación de los trabajadores, existe la convicción de que el trabajador importa sólo como un medio para la obtención de utilidades, y de que a la empresa no le interesa su participación. Para el dirigente sindical, el empleador siempre puede imponer metas de producción sin contemplación alguna de la voluntad u opinión de los trabajadores. Para algunos dirigentes, más bien, participar en el manejo de la empresa es motivo de inseguridad laboral (el anonimato protegería al trabajador). Por lo pronto, su participación no tendría correspondencia con una mayor remuneración o mejores condiciones de trabajo. Con respecto a la eventual participación, se hace sentir el peso de la exclusión de los empleadores, cuya estrategia es. por el contrario, separar el manejo y la toma de decisiones al interior de la empresa de los trabajadores.

En las empresas pareciera existir un insuficiente desarrollo de una cultura organizacional que permita que el trabajo pueda ser evaluado adecuadamente y que facilite, que de acuerdo a su desempeño, el trabajador acceda a empleos de mayor responsabilidad. De acuerdo a G. Salazar:

'Es evidente que la capacitación en tecnologias de punta, al disociarse del sistema de promociones (al menos para la mavoría de los trabajadores de una planta industrial) termina por devaluar, en la mente del trabajador; la importancia crucial de la innovación tecnológica. Porque en los hechos, por encima de ella está siempre el poder de los jefes, concretizado, por ejemplo, en la imposición de los 'regalones' por sobre el rendimiento productivo o el nivel de capacitación logrado por el trabajador corriente'. (G. Salazar, op. cit. 1997)

Las promociones, en muchos casos son por relaciones de compadrazgo que poco tienen que ver con la eficiencia y eficacia del empleado. Esta falta de una organización empresarial racional, sin duda, funciona como un cuello de botella con respecto a las expectativas que los trabajadores puedan tener y parece estar vinculada a la política implícita de las empresas de exclusión y marginación del trabajador. El empleador percibiría como mayores los costos para la empresa de una mayor participación de los trabajadores que los beneficios que por mayor productividad podrían derivarse de ésta. La empresa. antes de crear los canales para que los mejores trabajadores suban a cargos de mayor responsabilidad, prefiere contratar a conocidos fuera de la empresa.

\section{4. La identificación con sus pares}

La imagen de los trabajadores, en sus aspectos positivos, por ejemplo, el respeto a su trabajo y a los otros trabajadores, se obtiene horizontalmente dentro del mismo estrato social o clase. Esto sugiere que el trabajador con sus pares. en su nivel y con la clase encuentra reconocimiento social y logra establecer una autoestima $y$ un mundo referencial que le permite proyectarse como persona. ${ }^{26}$ Entre los valores que destacan los dirigentes sindicales entrevistados

\footnotetext{
25 SERCOTEC: Trabajadores y Empresarios do la PY Ml trente a la Modemizicion Productiva: Sedie doenmentos de trabajo N" 30: SERCOTEC/CIASI: Enero 1994

26 Aungue también una ala proportón de trabagatores liene una baja valoracion del trabajo y siente que los trabajadores

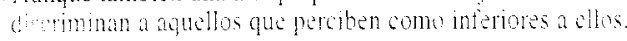


están la valoración del trabajo honesto y el énfasis en la dignidad del trabajador (identidad como trabajador).

\section{5. Tensiones entre estamentos ocupacionales}

Entre los trabajadores se menciona el nivel de educación como el criterio de discriminación más importante y que significa una marcada fisura entre categorías sociales y estamentos ocupacionales. Finalmente, se visualiza al estamento técnico y profesional y administrativo como más cercano a los empleadores. Esto no significa que los trabajadores de cuello azul identifiquen a los trabajadores de cuello blanco con la parte patronal. Es interesante que el hecho de que se reconozcan como trabajadores constituye un vínculo de identidad posiblemente más fuerte que la cercanía funcional de este estamento con los empleadores. Sin embargo, no puede desconocerse la existencia de tensión entre los estamentos que se manifiesta en la a veces cambiante definición de afinidades por parte de los dirigentes. sindicales consultados.

Los resultados de las encuestas parecen también indicar que esta autoestima se rompe en su relación con los empleadores. Los datos nos sugieren que la relación empleador-empleado determina en gran parte las bajas expectativas de progreso, capacitación, participación y de reconocimiento por la sociedad.

\section{6. Quiebre de la autoestima frente al empleador}

Los trabajadores sienten que tienen un carácter meramente instrumental para el empresario. Esto aparece como un círculo vicioso: por un lado, el trabajador siente que como persona no importa en la empresa y sólo orienta su actividad a asegurar su remuneración; por otro, para el empresario, el trabajador le aparece sólo orientado a su propio beneficio sin importarle la empresa. Esto lleva a que el empresario descalifique al trabajador. Sin embargo, una de las opiniones frecuentemente mencionadas por los dirigentes sindicales se refiere a la necesidad de los trabajadores de ser acogidos por la empresa. que se les reconozca como personas.

\section{7. Autoimagen de constituir un mero instrumento para el empleador}

Sin duda hay una distancia entre el éthos configurado a partir de las respuestas de los dirigentes sindicales y el concepto de éthos 'adecuado para el desarrollo' definido al inicio (éste se caracterizaría por una valoración de su trabajo, por la percepción de obtención de reconocimiento de sus empleadores y de otros trabajadores, por una actitud positiva con respecto a la capacitación y participación y por altas expectativas de progreso para él y los suyos).

\section{CARACTERIZACIÓN DE LOS ÉTHOS EMPRESARIALES EN CHILE}

Los empresarios adaptan métodos de producción desde el punto de vista de su propio éthos. Esta adaptación no tiene que ver necesariamente con las potencialidades de los recursos como son estos propuestos por los esquemas de producción modernos. Aparentemente, es la capacitación y participación de los trabajadores lo que permitiría un aumento mayor en la productividad de las empresas. Sin embargo. no ocurre así, dándose un mayor énfasis a la 
incorporación de capital constante y a una mayor intensidad en la utilización del trabajo. Habría una divergencia entre el éthos requerido por las relaciones económicas modernas y los éthos imperantes en la sociedad. La adopción. adaptación y por lo tanto la eficacia de los modernos sistemas de producción están condicionadas por los éthos existentes en la sociedad.

\section{1. Orientación al progreso y la modernidad}

El éthos empresarial ha sido caracterizado en otras investigaciones como orientado al progreso y la modernidad. Por parte de los empresarios, habría un deseo de estar al día en la tecnología principalmente sobre la base de incorporación de maquinaria. Esta orientación a la inversión en medios de producción de punta parece corroborada por los propios empresarios en los antecedentes recogidos por ENCLA98 (Tabla $\left.N^{0} 2\right)^{-7}$. Los empresarios se dan la más alta calificación en inversión en tecnología.

Tabla No 2: Autoevaluación empresarial de las inversiones en una escala de 1 a 7

\begin{tabular}{lcccc}
\hline & Tecnología & Ampliación de mercado & Capacitación de personal & Inversión en RR.HH. y Org. \\
\cline { 1 - 4 } & 5.4 & 4.3 & 4.2 & 3.9 \\
Microempresa(a) & 5.6 & 4.9 & 4.6 & 4.6 \\
Pequeña empresa & 6.0 & 5.2 & 5.2 & 5.1 \\
Mediana empresa & 6.2 & 5.3 & 5.7 & 5.4 \\
Gran empresa & & &
\end{tabular}

(a) Microempresa, 1-9 trabajadores: pequeña empresa, 10-49 trabajadores; mediana enpresa, 50-199 trabajadores; gran enpresa, 200 o más trabajadores.

Filente: ENCLA98

\section{2. La confianza en las nuevas máquinas}

Esta alta valoración de la tecnología por parte de los empresarios también fue identificada en el estudio exploratorio de CEPAL (1995) sobre imágenes sociales de la modernización y la transformación tecnológica. En este estudio se encontró que de acuerdo a los empresarios de los países consultados, las decisiones sobre incorporación de tecnología tienen que guiarse por razones estrictamente técnicas y económicas, sin dar lugar a otro tipo de consideraciones. Esto significa, de acuerdo a este estudio, que los criterios técnicos y la búsqueda de calidad son primordiales para responder en forma óptima a la demanda del mercado.

'El sector empresarial tiene una gran confianza en la eficacia de las nuevas máquinas, las cuales le aseguran el cumplimiento de sus objetivos primordiales. Se reconoce que lo más difícil es la administración del proceso, todo lo relacionado con las personas, y se asume que las fallas y errores son producto de la 'interferencia humana'. La tecnologia, en el fondo, asegura una perfección que sólo la máquina es capaz de proporcionar'. (CEPAL. 1995, op. cit.)

Es decir, la confianza en la tecnología corresponde a su forma de medios de producción y no a los aspectos vinculados a la capacitación de los trabajadores y a la organización del trabajo relativa a las modernas formas de producción.

27 ENCLA98: Encuesta Laboral: Infome Ejecutivo: Departumento de Estudios. Dircceión del Trabajo: Noriembre de 1998.

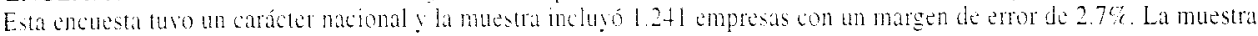
incluye sólo empresas formales 


\section{3. Resistencia a entregar participación a los trabajadores}

También este estudio de CEPAL (1995) concluye que los empresarios no parecen dispuestos a dar cabida a los trabajadores, mediante nuevas formas de coparticipación o cogestión, en el manejo tecnológico de la empresa. Los empresarios tienden a definir el liderazgo económico como algo que les pertenece exclusivamente. Para el empresario la empresa surge de la imaginación y coraje del sujeto empresario y no es imaginable compartir ésta con el trabajador. Por lo pronto, en América Latina, la visión de los empresarios como protagonistas principales del desarrollo de la empresa y únicos responsables en la toma de decisiones, hace muy difícil el rediseño de procesos y la incorporación plena de la Tecnología de Información (que implica la necesidad de intercambio de información con doble sentido entre los distintos niveles jerárquicos y funcionales).

En este estudio de CEPAL (1995) los dirigentes sindicales perciben que la decisión sobre el tipo de desarrollo y modernización tecnológica, y el modo de concretarla, están determinados por los empresarios, que por lo común adoptan decisiones guiados exclusivamente por sus propios intereses. Estos, no necesariamente corresponden a los del grupo obrero ni a intereses sociales globales.

En la encuesta de la ACHV (D. Burnett, ACHV, op. cit., 1998), en relación a la motivación de los empresarios para generar instancias de participación para sus trabajadores, los dirigentes sindicales encuestados mencionan que:

- Los empresarios se orientan a poner metas de producción más que a incorporar la participación de los trabajadores;

- Habría discriminación hacia el trabajador al que se le considera como menos que las gerencias; no se valora su experiencia; más bien se le considera un enemigo o un riesgo (en términos del control de la información al interior de la empresa); se descalifican sus capacidades;

- No se reconocen sus contribuciones;

- De acuerdo a algunos entrevistados no se involucra a los trabajadores por temor a que tenga que pagársele más. Se intenta promover la participación sin ofrecer los canales ni los incentivos que se requieren;

- Se contemplan incentivos materiales para aumentar la productividad pero sin incorporar al trabajador en los procesos de toma de decisiones;

- Se privilegia la inversión en maquinaria más que a esquemas participativos. En todo caso la orientación sería al ahorro de mano de obra más que a incorporar a los trabajadores.

\section{4. Poca prioridad de la capacitación para el empresario}

Las empresas priorizarían principalmente la inversión en maquinaria para mejorar la productividad. Las empresas ni siquiera hacen uso de las franquicias tributarias disponibles para capacitar a sus trabajadores y la capacitación que se realiza al abrigo de estas franquicias no estaría necesariamente focalizada con criterios de eficacia técnica y económica. También se argumenta que la capacitación se concentra en la realización de eventos y seminarios o a capacitar al estamento administrativo y no se considerarían esquemas de capacitación de obreros. ${ }^{28}$

\footnotetext{
28 Es de esperar que la reciente iniciativa de crear comités paritarios de capacitación tenga efectos en hacer accesible la capacitación a todos los estamentos de trabajadores y a adecuar ésta a los requerimientos reales de los trabajadores, mejorando su posicionamiento en el mercado de trabajo. Estos comités constituidos por representantes de la gerencia y los trabajadores, tienen la función de concordar programas de capacitación y debcrán constifuirse en todas las empresas que tengan una dotación igual o superior a 15 trabajadores. Además poseen un incentivo adicional que incrementa en $20 \%$ el subsidio para la ejecución de programas concordados. Sin embargo hay que tener claro que bajo el actual normativa la capacitación es una decisión privativa de los empresarios y vinculada a la productividad en las empresas.y no al desarrollo profesional de los rabajadores.
} 
La investigación de PROCAL (1993) realizada en 315 compañáas. reveló que en la mayoría de las organizaciones no hay un plan formal de capacitación ni tampoco un método adecuado para detectar las necesidades a este respecto. El estudio también reveló que si bien el $82 \%$ de las compañías encuestadas tienen un departamento de recursos humanos. sólo un 37\% de ellas ha definido políticas en la materia (en particular, existirían debilidades en evaluación de desempeños y sistemas de incentivos). Cuando se les preguntó a los encuestados qué importancia le asignaban en su empresa a las distintas áreas - venta. producción. personal. marketing. contabilidad o finanzaslos recursos humanos fueron clasificados en cuarto lugar y a una distancia notable de ventas. Se observó una disociación entre la conciencia que dicen tener los ejecutivos en cuanto a la importancia que le dan a los empleados en la elevación efectiva del nivel de competitividad de la empresa. y lo que realmente hacen para entregarles esa posibilidad. Este estudio concluye que el mayor problema radica en el paso de las ideas a la acción. lo que requiere un profundo cambio de actitud del secior empresarial. ${ }^{20}$

ENCLA98 incluyó preguntas de autoevaluación empresarial, en una escala de uno a siete. respecto a los esfuerzos realizados por la empresa en diversas áreas: tecnología. capacitación al personal, ampliación de mercados y recursos humanos y desarrollo organizacional. Los resultados pueden apreciarse en la Tabla $N^{\circ}$ 2. En la autoevaluación de las empresas, la capacitación de personal e inversión en recursos humanos y organización aparecen en un lugar muy por debajo de la inversión en tecnología. y también por debajo de las inversiones en ampliación de mercados (con excepción de la gran empresa que se evalúa con una más alta calificación en estos rubros frente a las inversiones en ampliación de mercados). En la medida que el tamaño de las empresas consultadas es mayor. mejoran sus calificaciones.

Pero más interesante que la autoevaluación de las empresas con respecto a la capacitación. es la distancia que media entre ésta y lo que efectivamente han realizado en este campo. El hecho de que las empresas se autoevalúen con una alta calificación en capacitación no significa que le den prioridad a ésta. $44.8 \%$ de las empresas que se calificaron con nota entre 6 y 7 (buena calificación) en capacitación no ofrecieron capacitación a sus empleados en los últimos doce meses anteriores a la encuesta. En un $66.8 \%$ de aquellas empresas que se calificaron con notas entre 4 y 5.9 (regular) no hubo capacitación durante este mismo período, proporción que aumentó a $82.1 \%$ para aquellas empresas que se calificaron con notas menores a 3.9 (deficiente) ${ }^{30}$

De acuerdo a la Encuesta CASEN 1994 (Tabla No 3), aquellos que declaran haber realizado alguna capacitación en el último año alcanzan al $15.3 \%$ de los entrevistados, concentrándose en las categorías de profesionales. De acuerdo a estos antecedentes la capacitación está concentrada en aquellos trabajadores con contrato indefinido, disminuyendo drásticamente para todas las otras categorías. Este tema es de gran relevancia. en la medida que el nuevo empleo se concentra en aquellas categorías de contratos temporales, dándose una disminución efectiva de los trabajadores cubiertos por contrato indefinido.

29 PROCAL; "Diagnóstico de Calidad Total en Chile": en Extensión desde el Cenuro: ocubre de 1993: Centro de Extensión de la Universidad Católica 1993

30 La diferencia entre ha percepción de su desempeño por parte de la empresa y las realizaciones efectivas en el tema de recursos humanos es mayor aun que en el caso de capacitación: 71 te de las empresas que se dieron una buena calificación en recursos humunos no cumplía con sala eunt. 
Tabla $N^{\circ} 3$ Categorías de empleo en Chile y capacitación laboral, 1994

\begin{tabular}{lrrrc}
\hline Status en el trabajo & Número & $\begin{array}{c}\text { Porcentaje } \\
\text { Del total }\end{array}$ & Del tipo & $\begin{array}{c}\text { Capacitación } \\
\text { último año }\end{array}$ \\
\hline 1. Asalariados estables protegidos & 2.460 .394 & 48.5 & 23.6 & \\
1a Profesionales & 569.770 & 11.2 & 23.2 & 42.2 \\
Ib No profesionales & 1.890 .624 & 37.3 & 76.8 & 18.1 \\
2. Asalariados inestables protegidos & 419.887 & 8.3 & 10.0 & \\
2a Profesionales & 35.077 & 0.7 & 8.4 & 30.7 \\
2b No profesionales & 384.810 & 7.6 & 91.6 & 8.0 \\
3. Asalariados no protegidos & 737.497 & 14.6 & 6.3 & \\
3a Profesionales & 39.954 & 0.8 & 5.4 & 25.2 \\
3b No profesionales & 697.543 & 13.8 & 94.6 & 5.1 \\
4. Temporeros & 128.273 & 2.5 & 2.5 & \\
5. Cuenta propia & 1.162 .854 & 22.9 & 6.0 & \\
5a Profesionales & 84.354 & 1.7 & 7.3 & 22.2 \\
5b No profesionales & 1.078 .500 & 21.3 & 92.7 & 4.7 \\
6. Empleadores & 159.684 & 3.2 & 8.8 & \\
6a Profesionales & 15.911 & 0.2 & 10.0 & 19.2 \\
6b No profesionales & 143.773 & 2.8 & 90.0 & 7.6 \\
\hline Total & 5.068 .589 & 100.0 & & 15.3 \\
\hline
\end{tabular}

Fuente: OIT-ETM con base en datos de MIDEPLAN (CASEN 1994) en: OIT, 19983!.

\section{5. Desconfianza hacia el trabajador (clasismo y racismo)}

Esta confianza en la eficacia de las máquinas y esta exclusión a toda participación de los trabajadores se afirma en las características de las máquinas que garantizan un volumen y calidad de producción. También en la desconfianza que se manifiesta en la necesidad de controlar información, la que en las negociaciones con los trabajadores podría ser utilizada contra los empleadores (información que además posee un carácter 'confidencial' para la empresa con respecto al Estado y la competencia). Pero esta resistencia a entregar información, de acuerdo a dirigentes sindicales de Correos y del Plástico de Chile, también se basa en una percepción de los trabajadores como enemigos y se asienta en un fuerte clasismo y racismo que se manifiesta en una consideración del trabajador como inferior a la clase patronal. En ese sentido la modernización de las enpresas también sigue el patrón de relaciones entre las clases a partir de la visión que los empleadores poseen de las clases trabajadoras.

\section{6. Visión heroica y protagónica de sí mismo}

Esta visión de los empresarios de los trabajadores como 'enemigos' encuentra su contraparte en una percepción 'heroica' de sí mismos como creadores de sus empresas y protagonistas del proceso de desarrollo que ha vivido Chile en los últimos quince años. En este sentido, el éthos empresarial estaría conformando las relaciones de producción. 


\section{7. Efecto en la organización del trabajo de las imágenes sociales de los empresarios}

De acuerdo a la encuesta a dirigentes sindicales (D. Bumett. ACHV, 1998), los empresarios no valorizan la participación y tampoco la capacitación de los trabajadores. lo que también tiene como efecto que la organización de la empresa aparezca subdesarrollada en la gestión de los recursos humanos (sistemas de capacitación y promoción de personal). Finalmente, tampoco se asigna ninguna prioridad a la estabilidad ocupacional. Es decir, en todos aquellos aspectos que apuntan a establecer una comunidad de intereses entre trabajadores y empleadores, la opción de los empleadores es la de someter más que incorporar a los trabajadores a las necesidades de la empresa.

En síntesis, esta brecha cultural entre las clases estaría detrás de algunas características de la vida empresarial en Chile. tales como la insuficiencia de carrera funcionaria en las empresas, la poca importancia de la capacitación en la promoción a mejores puestos de trabajo. el carácter de la capacitación vinculada a la productividad de la empresa y no a la formación profesional del trabajador, la no consideración del trabajador en la incorporación de nueva tecnología, el favoritismo de los jefes que recae en los trabajadores del estamento administrativo, etc. La poca valoración del trabajo por parte de los empresarios. en particular del trabajo del obrero, puede explicar en parte que los trabajadores tengan bajas expectativas de capacitación. De acuerdo a los dirigentes sindicales, los empleadores (y aquí habría que incluir los cuadros intermedios) aprovechan los conocimientos y experiencias de los trabajadores. pero sin entregarles capacidad de decisión, es decir en un plano marginal y directamente instrumental.

\section{LAS DISTANCIAS ENTRE EL ÉTHOS ESPERADO Y EL ÉTHOS OBSERVADO}

Más arriba en el párrafo sobre 'preguntas de la investigación', habíamos planteado que un trabajador que posea un éthos adecuado a las relaciones económicas que existan en un momento dado. tendrá una mayor productividad y. más allá de su empresa, se posicionará mejor en el mercado de trabajo, con los beneficios esperados para sí mismo y su familia. La aspiración para capacitarse y lo que esté dispuesto a realizar para obtenerla serán parte constituyente de su éthos. En la misma medida, un empresariado que valore el trabajo y que estuviese orientado a incrementar la productividad del trabajador a través de la capacitación y de entregarle responsabilidades y autodeterminación en el ámbito de su actividad de trabajo, también estaría en condiciones de aprovechar mejor las oportunidades que los modernos sistemas de producción ofrecen, conformando simultáneamente un éthos funcional al desarrollo económico.

Los resultados de las encuestas nos plantean algunos temas que revisten bastante interés. No es de menor importancia que de acuerdo a una mayoría de los dirigentes sindicales los trabajadores presenten bajas expectativas para sí mismos y los suyos. que se encuentren pobremente motivados para capacitarse y para participar en las empresas en que trabajan, que sus relaciones con los empresarios sean principalmente de desconfianza. En casos extremos habría una actitud fatalista del trabajador (vivir para mantener su familia. y conformarse con lo que hacen día a día. sin proyectarse a futuro). Sobre todo. es relevante destacar la opinión de los dirigentes sindicales de la baja motivación para capacitarse por parte de los trabajadores. Esto reflejaría una renuncia a su propia capacidad de desarrollo como persona. La importancia de esto no puede subestimarse. no sólo para el desarrollo del país. sino que para la fábrica social que se está creando. Finalmente. es frecuente que los trabajadores reconozcan una identidad con sus pares y ésta es fuente de auto valoración que muchas veces parece romperse frente a los empleadores. 
Por otra parte, los empresarios aparecen con una fuerte orientación protagónica, profesando un modernismo basado en la fe en la máquina, centralizando las decisiones y dando una relativamente baja prioridad a la capacitación de los trabajadores y prácticamente ninguna a su participación. Un aspecto muy relevante es una imagen del trabajador consolidada en un sentimiento clasista y racista en que a menudo éste es visto como un enemigo. Esta visión autoritaria y excluyente se manifiesta en una reticencia a entregar información a los trabajadores y en la organización misma de la empresa (deficiente desarrollo institucional que es excluyente de los trabajadores de cuello azul). En esta visión clasista, se favorece al personal administrativo y técnico profesional y se utiliza el favoritismo hacia otros estamentos.

\section{Los factores recurrentes en las respuestas de los dirigentes sindicales frente a las variables de valorización del trabajo, capacitación, participación, expectativas de progreso}

El análisis hecho arriba no estaría completo sin un intento por establecer sintéticamente los factores que están presentes en las respuestas a las preguntas iniciales sobre valoración del trabajo, expectativas de progreso de los trabajadores, participación, capacitación, relaciones entre empresarios y trabajadores. Estos factores serían:

- La inseguridad de mantener la fuente laboral con todo el temor que significa para el trabajador. Esta inseguridad no permite al trabajador proyectarse a largo plazo en la empresa. Tampoco el empresario estaría motivado a invertir en un trabajador del que puede prescindir o que va a cambiar de empleo.

- La percepción de bajas remuneraciones desmotiva a los trabajadores a capacitarse y a participar en la empresa. Los trabajadores perciben que la empresa no está dispuesta a compensar con mejores remuneraciones su capacitación y participación. Para la empresa, en el mejor de los casos, la capacitación sería un requisito de empleabilidad pero no de aumento de remuneraciones (aunque resulte en un incremento de la productividad del trabajador).

- La idea de que la empresa no reconoce las contribuciones de los trabajadores. Los trabajadores sienten que no son tomados en cuenta o sus contribuciones son plagiadas por sus superiores directos. Esto no estimula la participación del trabajador y se relaciona con la falta de desarrollo institucional en muchas empresas (adecuada definición de los roles y requisitos de los distintos puestos de trabajo en la empresa).

- La larga jornada de trabajo que no permite invertir tiempo en Capacitación o participación (muchas empresas no otorgan las facilidades durante la jornada de trabajo normal para que sus trabajadores se capaciten).

- La desconfianza entre empleadores y trabajadores. Este factor posee diversas lecturas: en tanto signifique entregar información a los trabajadores que puede resultar en su utilización por estos para respaldar sus peticiones reivindicativas frente a la empresa. Este temor explicaría la resistencia del empleador a entregar participación a los trabajadores.

- La empresa privilegia la inversión en maquinaria y asume que lo único que puede andar mal en las empresa es el factor humano. Éste. en vez de desarrollarlo es necesario controlarlo. Esta 'modernidad' de parte de la empresa no estimula ni la capacitación ni la participación, ni contribuye a las buenas relaciones entre empleadores y empleados.

- El clasismo y racismo establece distancias difícilmente franqueables entre estamentos ocupacionales, pero principalmente entre empleados y empleadores. Este clasismo y racismo está detrás del favoritismo de los empleadores por los empleados de cuello blanco pero afecta en mayor o menor grado a todos los estamentos ocupacionales.

- La sensación del trabajador de no ser más que un instrumento para la empresa impide su 
identificación con ésta y por lo tanto tiene efectos en su participación en la vida empresarial. El trabajador siente que como ser humano no cuenta, que es despreciado por el empleador. Al trabajador se le percibe como de segunda clase e incluso como un enemigo o como inferior intelectualmente.

- El trabajador no se siente acogido en la Empresa, que es una motivación importante paraél.

- El temor del trabajador, producto de su extrema vulnerabilidad frente a la política de empleo de la empresa. lo lleva a sustraerse de participar en la empresa y a procurar consolidar sus opciones a nivel de su sucesión (educación para sus hijos).

- Los trabajadores piensan que la empresa prefiere buscar personal capacitado en el mercado más que capacitar a los propios trabajadores;

- Percepción de que la empresa posee una orientación a metas más que a participación;

- Los empleadores se resisten a delegar y más bien tienden a realizar todas las tareas de responsabilidad ellos mismos;

- La impresión de la existencia generalizada de favoritismo en la empresa hacia el personal administrativo y la selección arbitraria entre éstos para las promociones y también para la designación de participantes en esquemas de capacitación;

- Esto estaría detrás de un insuficiente desarrollo organizacional institucional que no permitiría una carrera funcionaria en la empresa. Los ascensos no se realizan de acuerdo a criterios establecidos de funciones y capacidades requeridas, sino que a través del compadrazgo. En ese sentido, la falta de un desarrollo organizacional de la empresa funciona como un freno a las motivaciones de capacitación de los trabajadores.

- Percepción de que los cursos de capacitación son irrelevantes, no bien focalizados en el grupo objetivo o simplemente muy teóricos;

- Percepción de que el trabajo no es valorado por los empleadores;

- La falta de información por parte de los empleados, especialmente de los obreros sobre sus derechos y en particular sobre las oportunidades que la ley ofrece para capacitarse. Esta falta de información es generalizada en las PYMES y micro-empresas. Esta falta de información dificulta que los trabajadores comprendan las ventajas de capacitarse para mejorar su posición en la empresa y su empleabilidad futura.

- Estas variables estarían afectando tanto la motivación de los trabajadores para capacitarse. participar y su percepción de la relación con los empleadores como sus expectativas de progreso para sí mismos y los suyos.

\section{LOS FACTORES A SER CONSIDERADOS EN LOS PROGRAMAS DE CAPACITACIÓN}

La caracterización de las condiciones de trabajo mencionadas arriba sugiere una serie de medidas que permitirían un desarrollo de un éthos de trabajo en Chile orientado a la capacitación. a la participación y con altas expectativas. Desde luego, algunas de éstas serían:

6. 1. Perfilar políticas de capacitación que mejoren su calidad y que efectivamente se adecúen a las necesidades de producción y las características de los trabajadores usuarios de estos esquemas. Esta capacitación debería considerar a los trabajadores de cuello azul para los que no existe la capacitación requerida y que sólo marginalmente acceden a ésta. Se asume aquí que, en principio, la capacitación debe centrarse en la voluntad libre de los trabajadores en la perspectiva de formación profesional, mejorando su empleabilidad. Para ello se requiere estandarizar la capacitación permitiendo su certificación. 
6.2. Dado que el principal referente de reconocimiento social y de autoestima del trabajador son sus pares, las políticas y programas de capacitación han de considerar las organizaciones de carácter horizontal y solidario de los trabajadores, en particular las organizaciones sindicales, para convenir medidas de capacitación a nivel nacional, sectorial y de empresa. Se trata de que la capacitación constituya al trabajador como un actor social reconocible que considere su naturaleza distinta en términos de las relaciones de producción y de las relaciones de propiedad. En este sentido la capacitación ha de contribuir a constituir un éthos laboral distintivo. Aquí se sostiene que las diferencias de clase no pueden obviarse, por el contrario, se trata de contribuir a la creación de un referente de identidad funcional (aumentar las capacidades de producción de los trabajadores, lo que es fuente de identidad frente a sus pares). La privatización de la empresa de teléfonos de México de la que da cuenta G. Labarca es un ejemplo interesante de participación sindical en el sistema de capacitación avanzado. El sindicato, en este caso, se comprometió a mejorar la productividad a cambio de asegurar el empleo de todos los trabajadores como resultado de la privatización. Para que el sindicato pueda participar en esquemas de modernización productiva ha de obtener la capacidad técnica y buscar formas colaborativas con la empresa, abandonando estilos confrontacionales (G. Labarca, op. cit. 1998).

6. 3. Con respecto a la tensión entre estamentos y niveles ocupacionales, es necesario relevar aquellos aspectos de los modernos sistemas de producción que probablemente han sido más subestimados en Chile. En particular al trabajo en equipo que el rediseño industrial y la incorporación de las nuevas tecnologías de información hacen posible. ${ }^{32}$ Por un lado, el trabajo en equipo requeriría la incorporación de personal con diferentes niveles de calificación en una misma unidad o subunidad, en tanto, por otro lado, los flujos de información que la tecnología de información hace necesarios trastoca los patrones más asimétricos de información del tipo directrices que los rangos superiores envían a los inferiores y de informes con que los inferiores responden a los superiores. Finalmente el trabajo en equipo requiere una mayor profesionalización de sus miembros.

6. 4. Frente a la necesidad manifiesta de los trabajadores de ser 'acogidos' en la empresa y dado las relaciones sentidas de exclusión de los trabajadores por parte de los empleadores, la capacitación puede constituir un puente que permita al trabajador sentirse reconocido por la empresa y que tiene un espacio para su desarrollo y para su identificación con la empresa. Sin embargo, esta identificación con la empresa tendrá que partir por reconocer primero la identidad de los trabajadores como colectivo mencionado más arriba.

6. 5. Como condición necesaria para lograr ese objetivo, la capacitación ha de vincularse con su reconocimiento efectivo por parte del empleador. Esto tendría que significar asegurar en primer lugar la empleabilidad del trabajador, en segundo lugar, asegurar su carrera funcionaria (incorporando el reconocimiento simbólico del mejor desempeño y de las mayores responsabilidades asumidas) y en tercer lugar, establecer bases realistas institucionalizadas en la empresa para un mejoramiento de las remuneraciones.

6. 6. Se ha de evitar aquella capacitación que no mejora la productividad del trabajador ni su futura empleabilidad, que no es considerada en su evaluación, ni resulta en la posibilidad de un incremento de sus remuneraciones. Este tipo de capacitación contribuye a la frustración del

\footnotetext{
32 Como demuestran a través de sus investigaciones Baba et al. las jerarquías crean diferencias culturales entre los grupos de trabajo que fomentan la mala comunicación y conclusiones erróneas sobre la naturaleza de los problemas que se enfrentan en el proceso de producción. El silencio (por parte del grupo de menor rango) y los estereotipos (por parte de los grupos de mayor rango) producen un sistema que se refuerza a sí mismo de mala comprensión y desconfianza. Baba et. al 1998 Op. cit
} 
trabajador. disminuyendo sus expectativas y afectando la relación con los empleadores, además de desprestigiar a la actividad de capacitación misma. Este es un tema de particular importancia en la mediana, pequeña y microempresa donde la carrera funcionaria es inexistente y donde el empleado a menudo es visto más como una posible competencia que como un recurso de la empresa cuya productividad puede aumentar.

6. 7. Estas son condiciones para que la capacitación resulte en una mayor profesionalización del trabajador que efectivamente signifique la adquisición de nuevos niveles de responsabilidad y de autodeterminación dentro de las competencias adquiridas. La capacitación, en la medida que efectivamente lleve a un reconocimiento profesional (con la adquisición de mayores responsabilidad y capacidad de decisión) es un paso importante en un aumento de participación de los trabajadores en la empresa.

6. 8. Un aspecto central que toda política de capacitación ha de enfrentar es la baja prioridad que los trabajadores le dan a la capacitación. Esta baja prioridad a la capacitación se relaciona con las bajas expectativas de progreso de los trabajadores. Si las expectativas son bajas los trabajadores no aspirarían a capacitarse. De acuerdo a los trabajadores, las bajas expectativas se vinculan a la falta de posibilidades de capacitación. la inestabilidad ocupacional, bajos ingresos, baja valoración por parte de los empleadores y falta de carrera funcionaria en la empresa. En nuestra hipótesis, bajas expectativas conforman una actitud de acomodar esfuerzo y medios a logros limitados. Sin embargo, también es necesario preguntarse si es que las expectativas de los trabajadores aumentarían de mejorarse las posibilidades de mayores ingresos, estabilidad ocupacional, carrera funcionaria, acceso a la capacitación, etc. En otras palabras, el acceso repentino a éstas no necesariamente significaría un aumento de las expectativas sino que un reacomodo del viejo patrón de expectativas a las nuevas condiciones de trabajo y remuneración (el patrón de expectativas tendría una elasticidad diferente a las condiciones materiales de vida), que puede resultar en realizar menos para mantener las nuevas condiciones de trabajo. El tema es de crear expectativas de logros equilibradas (contemplando los medios necesarios para alcanzarlos).

6. 9. En toda empresa, una proporción variable de trabajadores tiene un éthos favorable a la capacitación y al desarrollo económico. En términos de nuestra investigación el éthos observado en este grupo coincide con el esperado. Estos trabajadores poseen una alta valoración de sí mismos, presentan altas expectativas de progreso, tienen alta motivación para capacitarse y participar en la empresa y perciben como positiva las relaciones con los empresarios. Este grupo tiene una actitud positiva frente a su entorno y probablemente está en situación de aprovechar mejor que sus pares las oportunidades que el medio les ofrece. Estos naturalmente podrán constituir un polo dinámico dentro de la empresa capaz de elevar la autoestima y la motivación del resto de los trabajadores. Sin embargo, no ha de caerse en el tipo de relación de 'favoritismos' que los aislará de sus compañeros. Para que esto no ocurra sería conveniente cumplir con ciertos requisitos relacionados con la organización del trabajo en la empresa. En el caso de la Volkswagen de Puebla. relatado por G. Labarca. los líderes son constituidos por los gerentes, supervisores. capataces a cargo del proceso productivo. pero además se hacen responsables de la formación e información de las personas a su cargo. De esta manera se asegura que la información llegue a los escalones más bajos del proceso productivo y una atención más personalizada sobre el subordinado con respecto a su desempeño y necesidades de capacitación. De allí que se habría logrado una descentralización en particular de las decisiones de capacitación. (G. Labarca op. cit., 1998). 


\section{Condiciones materiales para ser consideradas en el desarrollo de un éthos laboral orientado a la capacitación}

- Aunque en este trabajo hemos dado una importancia determinante a los factores cuiturales en la formulación exitosa de políticas de capacitación. éstas no tendrán éxito sin considerar algunas condiciones laborales materiales. Aquí se asume que la provisión de estas condiciones no son suficientes para el éxito de esquemas de capacitación, sino que éstas han de ser acompañadas por un éthos laboral que aproveche las disponibilidades materiales:

- Mayor estabilidad del empleo: Esta es una condición para contrarrestar la inseguridad del trabajador y disminuir la competencia entre los trabajadores para conservar el puesto de trabajo. Además es una condición para lograr un trabajo en equipo que las nuevas tecnologías requieren y la identificación del trabajador con la empresa. El trabajo en equipo permite un reconocimiento social mayor a la contribución del trabajador.

- Administrar la extensión de la jornada de trabajo permitiendo la capacitación del trabajador durante la jornada normal. Esto se contradice con la enorme presión por aumentar la productividad del trabajador sobre la base de la remuneración variable que muchas veces implica prolongar la jornada de trabajo. El énfasis en la productividad del trabajo basado en su capacitación se contradice con los incentivos más inmediatos a la productividad basados en un aumento de la remuneración variable.

- Desarrollo institucional de la empresa que conlleve establecer una carrera funcionaria que permita la promoción del trabajador y el reconocimiento de su contribución. Esto significa asegurar la participación racional del trabajador y permite una limitación de favoritismos que caracterizan la empresa chilena basada en lazos de carácter familiar.

- Establecer canales de comunicación adecuados que permitan superar las relaciones de desconfianza entre empresarios y trabajadores, incorporando al sindicato en la gestión empresarial.

- Adecuados sistemas de capacitación

\section{BIBLIOGRAFÍA}

\section{R. Arnold}

M. Baba, D. Falkenburg, D. Hill.
'Cambios Tecnológicos y Organizativos en la Formación Profesional'; Proyecto Conjunto CEPAL/GTZ Políticas para Mejorar la Calidad, Eficiencia y Relevancia de la Educación Técnica y el Entrenamiento de América Latina y el Caribe (FRG/96/S38); Santiago de Chile 1998.

Cap. IX Cambio Empresarial: Dimensiones Culturales de las Nuevas Tecnologías; Innovación Tecnológica y Procesos Culturales; M. J. Santos, R. Díaz Cruz (eds.); Ediciones Científicas Universitarias: Horizontes y Paradigmas en Ciencia y Tecnología; UNA; Fondo de Cultura Económica: México, 1997

33 El empleo de por vida de la empresa japonesa habría hecho posible el desarrollo de los "círculos de calidad" y "productividad" y el espiritu de empresa que parece haber caracterizado su desarrollo industrial hasta la década de los ochenta. Finalmente aquellas empresas que buscan tener una planta minima en perídos de testricción económica. también son aquellas que con mayor dificulad responden a aumentos de la demanda. Por el contrario aquellas empresas que mantienen una planta estable de trabajadores son capaces de responder en mejor forma a las fluctuaciones cíclicas de la economía. 


\section{Burnett}

CEPAL

DESUC

\section{Dirección del Trabajo}

\section{Dirección del Trabajo}

\section{Dirección del Trabajo}

\section{Echeverría}

\section{R. Echeverría}

\section{ENCLA98}

\section{Encuesta DESUC}

\section{E. Faletto}

\section{F. Fukuyama}

Indicadores Económico Sociales

\author{
G. Labarca
}

\section{Larraechea}

\section{Morishima}

Modernización Productiva y éthos laboral; ACHV; 1998

Imágenes Sociales de la Modernización y la Transformación Tecnológica': Santiago de Chile de 1995

Dirección de Estudios Sociológicos Pontificia Universidad Católica de Chile. Consorcio Periodístico de Chile S. A. (COPESA), Estudio Nacional de Opinión Pública: Noviembre de 1995

'Temas Laborales'; Encuesta a Empleadores y Trabajadores 1996; Dirección del Trabajo; Departamento de Estudios; Año $3 \mathrm{~N}^{\circ} 7$. Septiembre de 1997

Temas Laborales; Departamento de Estudio: Año $2 \mathrm{~N}^{\circ} 5$. Enero 1997

Temas Laborales; Departamento de Estudios; Año 4, Nº 10 Septiembre 1998

'Subcontratación de la producción y subcontratación del trabajo'; Temas Laborales Año 3, № 7, septiembre de 1997; Departamento de Estudios. Dirección del Trabajo.

'Notas sobre el mundo empresarial de hoy'; PREALC No 374; Marzo de 1993

'Encuesta Laboral; Informe Ejecutivo'; Departamento de Estudios, Dirección del Trabajo; Noviembre de 1998

Octubre de 1998

'Panorama Social': Análisis del año 1998; Sociedad-políticaeconomía; Departamento de Sociología Universidad de Chile; 1999

'La Confiance en la Pusissance: Vertus sociales et prospérité économique': PLON. 1996

PET No 148 julio 1997

Formación para el trabajo en industrias mexicanas; Proyecto Conjunto CEPAL/GTZ Políticas para mejorar la calidad, eficiencia y la relevancia del entrenamiento profesional en América Latina y el Caribe' (FRG/96/S38): Santiago de Chile, 1998.

Director del Sence. Capacitación laboral más amplia y equitativa (entrevista): Tránsito Legislativo: Zona Pública: Secretaría de Comunicación y Cultura: 1997

'Why has Japan 'Succeded'? Western technology and the Japanese ethos': Cambridge University Press: 1984

'Chile Crecimieno. empleo y el desafio de la justicia social': 1998 


\section{Palomares, L Martens}

PNUD

PROCAL

G. Salazar

SERCOTEC

C. Vignolo F., G. Wechsler P.

M. Weber
'Cambios en la gestión y actitud empresarial en América Latina. Un marco de análisis'; Revista de Economía y Trabajo; Año $1 \mathrm{~N}^{\circ} 2$, Julio-Diciembre de 1993

'Desarrollo Humano en Chile 1998'; Marzo de 1998

'Diagnóstico de Calidad Total en Chile'; en Extensión desde el Centro; octubre de 1993; Centro de Extensión de la Universidad Católica

'Capacitación, competitividad e innovación tecnológica en Chile' (1976-1997); Proyecto Conjunto CEPAL/GTZ 'Políticas para mejorar la calidad y la relevancia del entrenamiento profesional en América Latina y el Caribe' FRG/96/S38; Santiago de Chile 1997

Trabajadores y Empresarios de la PYME frente a la Modernización Productiva'; Serie documentos de trabajo $\mathrm{N}^{\circ} 30$ SERCOTEC/CIASI; Enero 1994.

'La innovación tecnológica en Chile: lecciones de un estudio de casos de empresas manufactureras exitosas'; Universidad de Chile, Departamento de Ingeniería Industrial; Junio de 1992

'La Ética Protestante y el Espíritu del Capitalismo'; Ediciones Península: Barcelona; 1997 